\title{
"La Boîte à Joujoux" de Claude Debussy e a Diversificação Analítica*
}

\section{José Eduardo Martins}

Na totalidade das obras de Debussy, La boûte à joujoux é uma das que apresentam maior quantidade de referenciais, prestando-se às mais diversas possibilidades analíticas, que longe estão de um esgotamento. Essencialmente, La boîte à joujoux apresenta-se como produção de síntese de muitos dos procedimentos utilizados pelo compositor durante a sua trajetória anterior, sendo, igualmente, um passo rumo à direção voltada à simplificação, encontrável em muitas das criações posteriores.

Três das obras de Debussy, Khamma, Jeux e La boûte à joujoux foram compostas em um espaço de tempo relativamente curto, entre 1911 e 1913, pertencendo à categoria das obras dramáticas $e$ coreográficas, segundo François Lesurel. Harry Halbreich ${ }^{2}$ e Robert Orledge ${ }^{3}$ posicionam-nas entre as produções para cena e para o teatro, o que resulta basicamente na mesma classificação.

Khamma e Jeux foram concebidas para orquestra e tiveram, aprioristicamente, reduções para piano realizadas pelo autor. Para La boîte à joujoux teria havido um mesmo princípio, mas, sob outra égide.

Algumas questões relativas à classificação de La boûte à joujoux deveriam ser formuladas. Seria esta uma obra para piano solo ou uma redução? A textura pianística da mesma aponta para uma redução de obra concebida para orquestra, ou conteria os ingredientes próprios de uma obra composta visando o piano solo? Poder-se-ia entender a redução de La boîte à joujoux ao nível das reduções de Khamma e Jeux? Não se enquadraria a primeira, nomeada por musicólogos da maior respeitabilidade, em uma categoria que a minimizaria, graças a circunstâncias exteriores contratuais. que remontam aos começos de 1913?

Quando do catálogo citado da obra de Debussy, fundamentado na mais vasta documentação conhecida até então, François Le- 
sure situa La boîte à joujoux como redução, ficando a obra cm outra categoria que não a do piano solo ${ }^{4}$. Robert Orledge ratificaria o termo redução ${ }^{5}$. Bem anteriormente, Marcel Diétschy situaria este ballet pour enfants como criação para piano ${ }^{6}$.

La boîte à joujoux foi composta entre julho e outubro de 1913. Quase meio ano após, na primavera de 1914, iniciava Debussy a orquestração, que se prolongara até novembro de 1917 , quando o autor, em sua, talvez, última carta a Durand, escreveria: "(...) a orquestração está em fase de acabamento"7. André Caplet se encarregaria de finalizá-la após a morte de Debussy.

Primeiramente, seria necessário estabelecer-se uma comparação entre as duas outras reduções e a "redução" de La boîte à joujoux. A de Khamma apresenta-se acabada em 1912, tendo sick comercializada a partir de 1916. A redução de Jeux data de 1912. As edições de Khamma e de Jeux conservam, na página onde há créditos, endereços, regulamentos e Copyright by Durand et Cie. 1912, a indicação partition pour le piano réduite par l'auteur. Na página semelhante de La boîte à joujoux, tem-se apenas musique de Claude Debussy, sobre a aquarela de André Hellé, que representa a
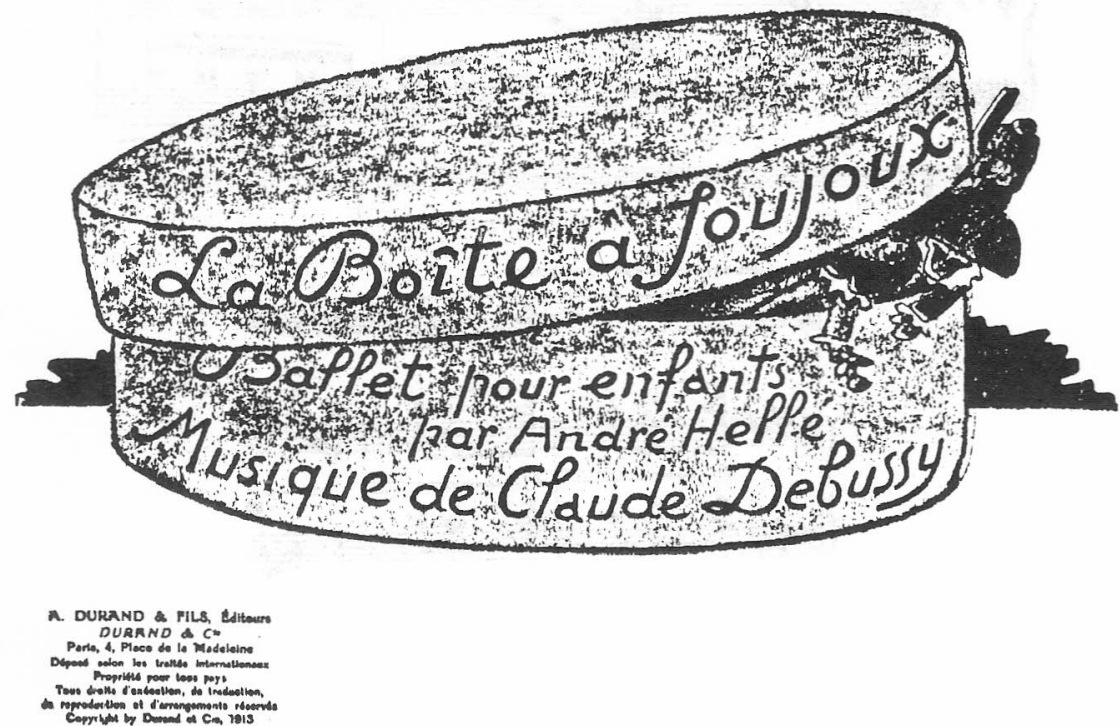
caixa de brinquedos. Não existe, pois, talvez não por acaso, a palavra redução.

Outra constatação verificada através do próprio conteúdo pianístico refere-se à real destinação, no caso, das três criações. $\mathrm{Ni}$ tidamente, em Khamma e Jeux, configura-se uma linguagem musical não propriamente pianística, sendo que, em determinados trechos, torna-se impraticável a realização ao piano unicamente por duas mãos. Tanto na lenda como no poema dançados, a redução de Debussy é quase que exclusivamente atenta àquilo que se deve passar na orquestração. Diferentemente dos três pentagramas do segundo caderno de Images, ou do segundo livro dos Préludes, a presença de três, ou mesmo quatro pentagramas em Khamma e Jeux, evidenciam a antítese de uma escrita real para piano solo.

Exemplo 1

(Éditions Durand)

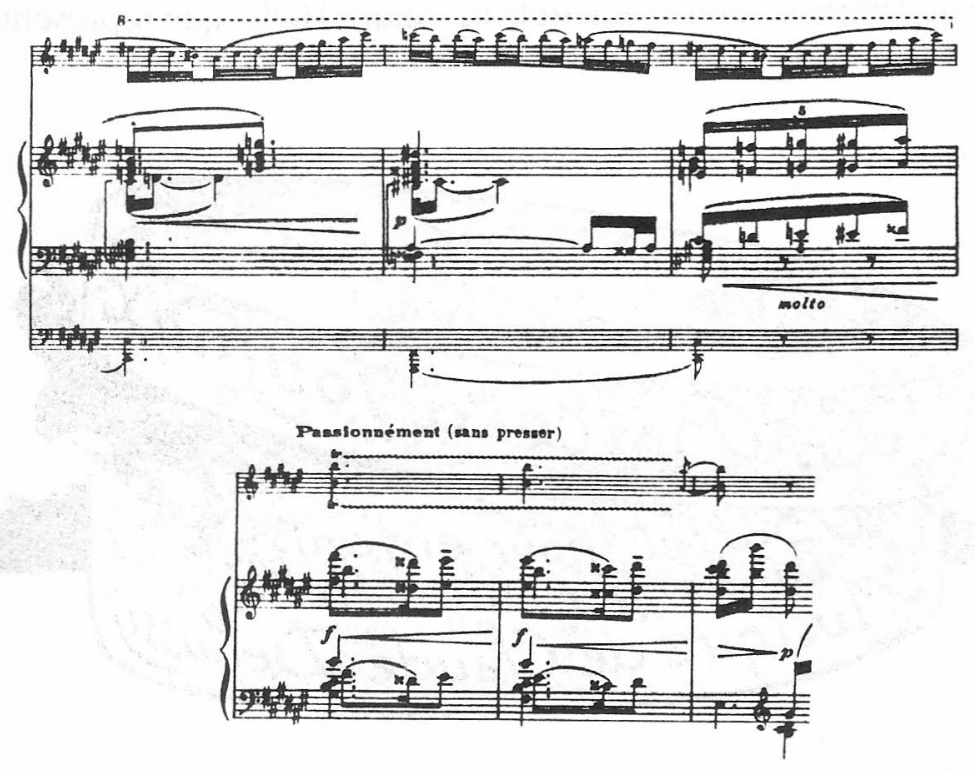


Exemplo 2

(Éditions Durand)

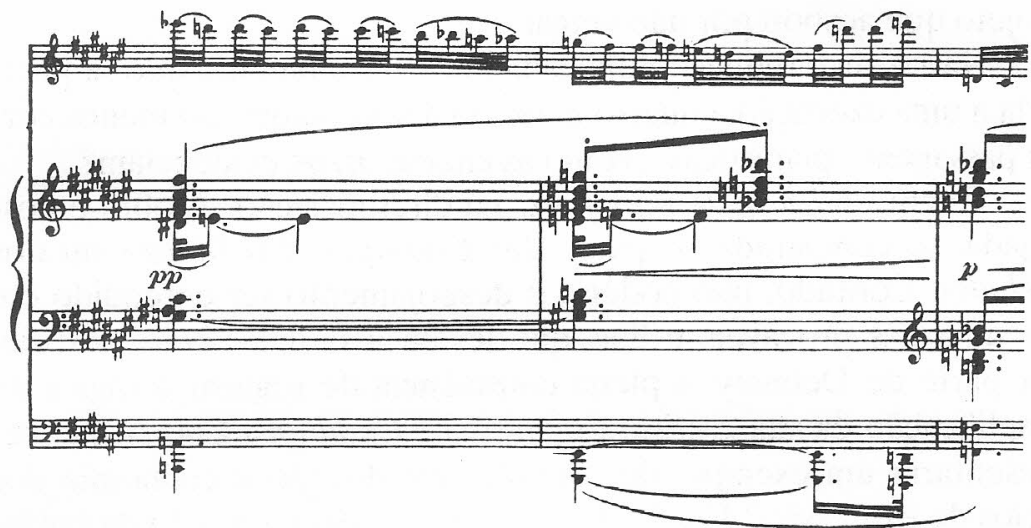

Khamma, aliás, mantém indicações de tremolos característicos da escritura dos instrumentos de cordas, mas não utilizados por Debussy na sua obra para piano solo.

Exemplo 3

(Éditions Durand)
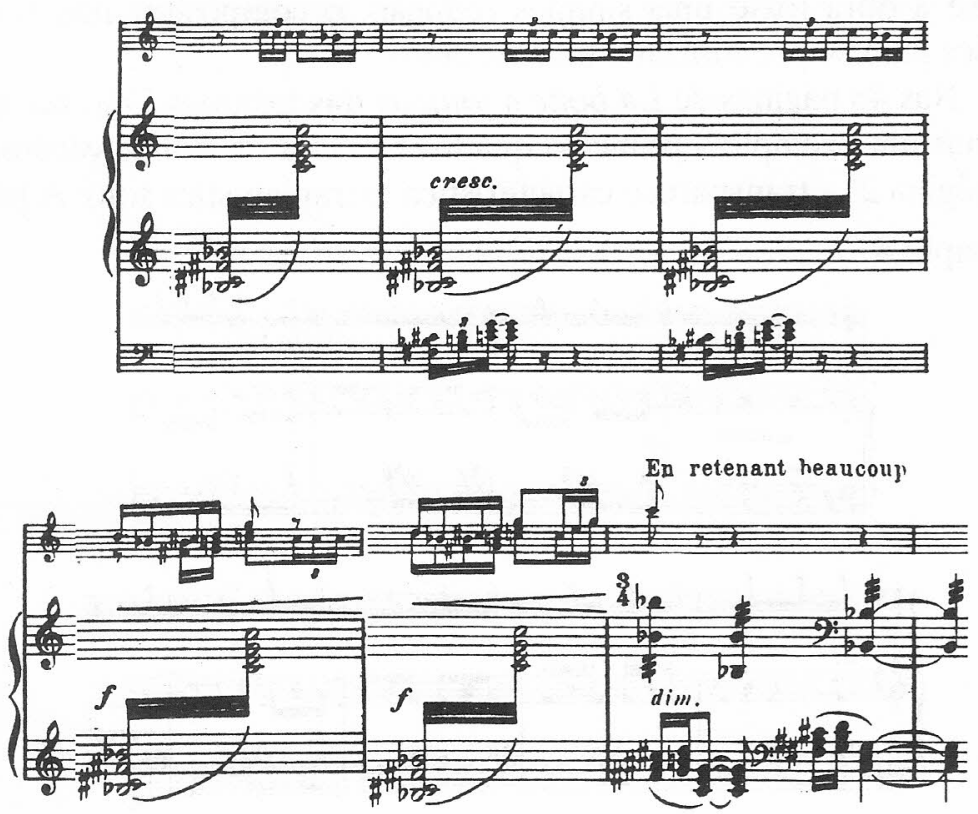
É provável que razões de ordem financeira do autor tenham determinado a proposta a Durand, de 3 de setembro de 1913, na qual Debussy pensara em uma transcrição para dois pianos de Jeux, projeto que acabou por não vingar ${ }^{8}$.

Não seria a redução publicada em 1912 uma obra que se prestaria a uma execução a quatro mãos ou a dois pianos, ao menos certas passagens "pianísticas", como as citadas assim evidenciam?

Quanto à La boîte à joujoux, há diferenciação. A obra é despojada, se comparada ao piano das Estampes, das Images ou dos Préludes. Contudo, não poderia o despojamento ser entendido como uma das prováveis trilhas que levam à síntese? Não existiria, por parte de Debussy, a plena consciência de realizar a lógica da simplificação da sua escritura pianística? Children's Corner não representaria um exemplo do caminho em direção à economia dos meios de expressão? Em $1^{\circ}$ de fevereiro de 1914, quando da entrevista para Comoedia, Debussy afirmaria que La boîte à joujoux seria "uma obra para divertir as crianças, sem mais"9 e, mesmo anteriormente, a Durand, aos 5 de setembro de 1913, em torno da elaboração da obra para piano solo, "eu tentei ser claro e mesmo divertido, sem pose e sem inútcis acrobacias" 10 , o autor evidenciaria confissões transparentes e rel'erência clara à pianística menos densa. Se a obra fosse uma simples redução, o compositor não teria razões para se pronunciar a esse respeito.

Nas 48 páginas de La boîte à joujoux das Éditions Durand, em apenas um exemplo - primeiro quadro na cena da Ronde générale, na página 21 - transparece característica extrapianística solo. A pasExemplo 4
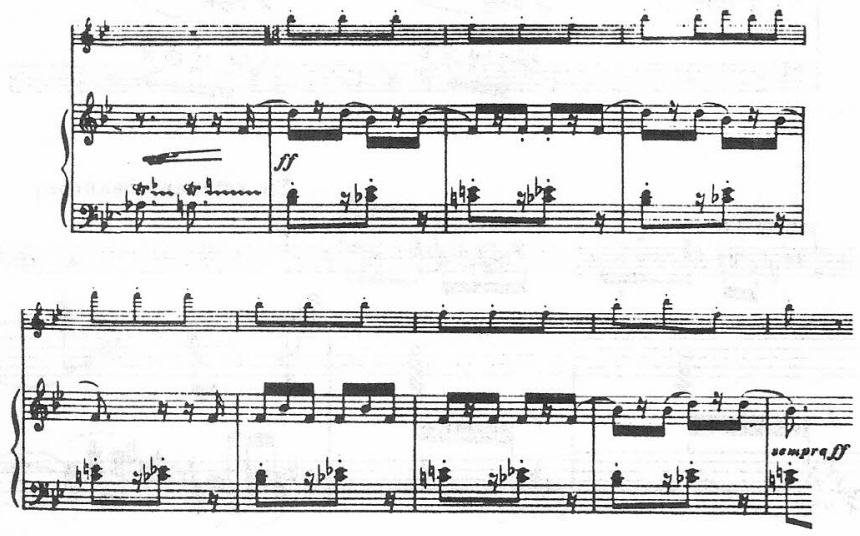
sagem está grafada em três pentagramas, apresenta dois planos melódicos de conotações militares ritmicamente diversos, sustentados por terças paralelas que realizam oscilações.

$\mathrm{Na}$ verdade, "la simplicité naturelle"11, como afirmaria Debussy, e seus propósitos a respeito de um "divertido, sem pose", citado anteriormente, ocasionariam algumas das causas do julgamento equivocado que acompanhou La boîte à joujoux. As posições informais de Debussy foram compreendidas como ponto de partida para, até, uma depreciação no que se refere à obra. Edward Lockspeiser, citando inicialmente Debussy a respeito do ballet para crianças, afirma que La boîte à joujoux é “(...) uma obra menor, sem pretensão, que não visa em nada o refinamento da ópera para crianças de Ravel e Colette"'12. Entenda-se que se trata de opinião pessoal do especialista renomado, mas que serviu, infelizmente, de modelo. Harry Halbreich, sem buscar uma revisão do pensamento anterior, na análise da obra anexada à tradução em francês dos livros de Lockspeiser, não se aprofunda e justifica: “(...) não é necessário, dado o caráter particular da obra, fazer-se uma análise detalhada"'13. Acrescente-se que Halbreich fará a descrição da história a partir da partitura para piano de La boîte à joujoux. Robert Orledge posiciona-se contrariamente a esta minimização ${ }^{14}$, enquanto Marcel Diétschy lamentaria, em 1962, o fato "de jamais se tocar a obra", observando méritos na criação de Debussy ${ }^{15}$.

Torna-se, pois, possível acreditar que uma razão essencial e diminuída, concebida por alguns musicólogos, parte sem revisão das descontrações orais ou escritas voluntárias de Debussy, que, sob a égide da afeição paterna, externa sentimentos à sua fillha Chouchou. O lúdico infantil sugerido nas cartas e em entrevistas seria a evidência de uma tipicidade da obra. A minimização, aliada ao conceito da obra como redução, pode ter deixado à margem o ballet pour enfants, que é pensado pianisticamente e que é singular no conjunto das composições para piano de Debussy. Considere-se que pianistas ${ }^{\circ}$ musicólogos como Alfred Cortot, Robert Schmitz e Jorge Zulueta ${ }^{16}$ colocam La boîte à joujoux como autêntica obra para piano solo. 
ta, a duração mostra-se fundamental. Considerando-se a obra como escrita para piano solo, deve-se aceitá-la como a mais monolítica criação para piano de Debussy, ou seja, aquela onde o discurso apresenta-se ininterrupto, mesmo compreendendo-se os quadros diferentes.

Os dois cadernos de Images, os dois livros de Préludes e. os dois livros de Études, nos seus conjuntos, são mais extensos, mas tem-se, na realidade, coletâneas de peças relativamente curtas, sob o aspecto da duração, permitindo a Debussy edificar uma linguagem musical inusitada. Em geral, há momentos contrastantes entre uma peça e outra, títulos e textura musicais igualmente diferenciados, porém, cada imagem, ou prelúdio, ou estudo esgota em suas unitariedades o projeto individualizado do compositor, que buscará, finalmente, o agrupamento que possibilitará um outro descortino monolítico.

A duração de uma obra pode conter mais facilmente a essência dos antagonismos. Considerando-se a história de La boîte à joujoux, encadeada e programática, onde os personagens desfilam durante o discurso, poder-se-á entender o básico não-retorno ao já exposto, exceções havendo, mormente no Prélude e no Épilogue. Contudo, o não-retorno do texto evidencia, até, uma certa décalage em relação a pequenos segmentos estruturados em formas definidas, para determinadas cenas.

A pergunta a ser formulada atingiria as microestruturas formais: não conteria La boîte à joujoux, por vezes, em suas cenas, uma "forma" tradicional na grande estrutura desta criação? Fica evidente que na obra para piano de Debussy há a nítida preferência pela forma $\mathrm{A}-\mathrm{B}-\mathrm{A}$, raramente a freqüência à forma Rondó e outras categorias formais.

A narrativa que continua em La boîte à joujoux prolonga-se durante quase meia hora, permitindo revelar em segmentos precisos do ballet o exercício, por parte de Debussy, da forma A-B-A, mesmo que o texto, nos segmentos aludidos, continue. $O$ hábito à prática formal cria, pois, um "aparente" desequilibrio que, na realidade, apenas paradoxalmente reforça a unidade da obra como um todo. Frise-se que, quanto à duração, determinadas cenas ultrapassam as dimensões espaciais de obras outras de Debussy para piano solo. Considerando-se os compassos de Élégie, 21; The little shepperd e Danseusesde Delphes, 31; La fille aux cheveux de lin, 39; La 
terrasse des audiences ..., 45; Cloches à travers les feuilles, 49; Bruyères, 51; Brouillards'e Feuilles mortes, 52; Et la lune descend sur le temple qui fut, 57, verifica-se que a narrativa de La boîte à joujoux contém cenas que se prolongam sobremancira: La Ronde, 231; Danse de la poupée, 101, em sua forma A-B-A-coda tipilicada; Prélude initial, 76; La Bataille, 54. A quantidade de compassos pareceria circunstancial, se Debussy não caracterizasse - por causa da história - os personagens com os temas individualizados, quase sempre revisitados diferentemente.

Considere-se, ainda, que a duração prolongada de La boîte à joujoux permite a Debussy, em uma lógica aritmética, colocar em evidência um número considerável de citações de temas - não seus -, bem como o disfarce, consciente ou não, de conteúdos temáticos existentes em outros autores e, em acréscimo, determinadas melodias do cancioneiro popular. Por outro lado, a duração específica possibilita a retrospectiva dos próprios processos pianísticos de Debussy, revisitações do seu idiomático construído desde a juventude. Esses processos delimitam-se simplificados, mas contêm embriões - característica idiomática - do desnudamento que se pode, por vezes, perceber nas obras para piano compostas nos últimos anos.

Na produção de Debussy, La boîte à joujoux é, igualmente, depositária de parcela considerável de todo o acervo musical c extramusical do compositor. É possível que, não por acaso, Debussy tenha pretendido "arrancar as confidências das bonecas"17, como escreveria a Durand. Não seria esse "arrancar" o prolongamento de Debussy, não somente das experienciações lúdico-infantis, estas essenciais, mas também a reconciliação com toda espécie de informações depositadas em sua memória até 1913? Essa intuição, ou vontade de colocar na obra um número tão expressivo de referências, estabelece para La boîte à joujoux um manancial analítico que se presta ao multidirecionamento. Considere-se que Debussy, ao buscar os dados em sua memória, conta um pouco de si mesmo, seus gostos, suas preferências e mesmo - o que faz parte de um todo - o seu lado jocoso, lúdico e espontâneo.

$$
\text { *** }
$$

La boîte à joujoux tem sido objeto de vários estudos compara- 
tivos, no que se refere à temática musical, à terminologia e aos segmentos da textura musical, com a linguagem de autores que freqüentaram as idéias de Debussy. Entre os compositores russos que podem ter servido de modelo, dois se destacam: Moussorgsky e Stravinsky ${ }^{18}$. Quanto a este, buscaram-se aproximações entre $L a$ boîte à joujoux e Petrouchka. Lockspeiser e, posteriormente, Orledge apontam nessa direção. É certo que Debussy tivera uma admiração pela obra de Stravinsky. Em carta ao compositor russo, de 5 de novembro de 1912, refere-se à obra: "(...) e que a seu amigo, Chouchou compôs uma fantasia sobre Petrouchka que faria os tigres rugirem"19 . É possível, também, que não por acaso La boîte à joujoux estaria destinada à representação por marionetes, assim como a obra citada de Stravinsky. Lembre-se de que Debussy, em carta ao autor russo, afirmaria em abril de 1913:

Graças a você, eu passei prẹciosas férias de Páscoa em companhia de "Petrouchka", do "Maure" terrível e da deliciosa 'Ballerine'. Imagino que você deva ter passado incomparáveis momentos com estes três bonecos" 20 .

A linguagem desnudada de La boîte à joujoux poderia suscitar hipóteses comparativas de obras outras de Stravinsky, que não $P e-$ trouchka. Quando Stravinsky e Debussy tocaram Le Sacre de Printemps a quatro mãos em casa de Louis Laloy, em abril de 1913, tornou-se evidente ter o compositor francês ficado impressionado ${ }^{21}$. Pouco após, escreveria Debussy a Stravinsky:

Eu conservo ainda em minha memória a lembrança da execução do seu Sacre de Printemps em casa de Laloy ...isto me (hante) como um belo paralelo e eu tento, inutilmente, reencontrar a terrível impressão 22 .

Frise-se que, algumas semanas após, Debussy começaria a compor La boîte à joujoux.

Estar aberto para o novo foi uma das constantes em Debussy. Após a idéia fixada, no momento em que ele sentia a necessidade de colocar a criação no papel pautado, a filtração de certas admirações poderia se verificar de acordo com a destinação da obra. Em La boîte à joujoux, onde o despojamento é consciente, houve a 
possibilidade de Debussy aceitar algumas propostas que existem em Sacre de Printemps.

Uma das características mais evidentes em Sacre é essa rítmica sauvage. Mudanças de métrica, decalagens rítmicas, acentuações assimétricas percorrem a obra. Conscientemente Debussy não iria, em 1913, em criação onde a simplicidade põe a obra a nu, demonstrar a admiração pelo aspecto rítmico e métrico do autor russo, facilmente detectável, mesmo que estivesse sob impacto. Se Jeux e o terceiro dos Caprices en Blanc et Noir, este dedicado não sem razão intencional a Stravinsky, oferecem exemplos de afinidades - sobremaneira o Caprice -, poder-se-ia alegar para os dois casos um outro fórum de debates, pois outros são os desideratos de Debussy.

Para La boîte à joujoux teria reservado, talvez, a sutileza mesma das afinidades. E, neste domínio, a melodia, a temática pareceriam ser o caminho consciente ou não das aproximações de $S a$ cre com La boîte à joujoux. Seria igualmente, talvez, a simplicidade dos contornos de determinados temas stravinskianos em Sacre que estariam eleitos no mundo interior de Debussy.

Na sua obra para piano há, aproximadamente, duas dezenas de criações que começam com uma melodia desacompanhada, como em The little shepperd, ou ainda em intervalo de oitava, como Hommage à Rameau, ou mesmo em paralelismo de acordes, como Et la lune descend sur le temple qui fut. O princípio pode ter sido o mesmo. A duração de La boîte à joujoux, devido ao prolongamento de uma história onde a ação é próxima à realidade, favorece os temas desacompanhados ou apenas sustentados por centro tonal. As características de certos monólogos, é possível, permitem a aproximação com Stravinsky de uma maneira mais facilmente apreensível e, frise-se, na essência do isolamento temático, isto posto, a nível melódico. Pense-se nos monólogos "arrancados" a partir das confỉências das bonecas. A aproximação se realizaria através dos contornos de certos temas, da possibilidade interválica, das apogiaturas ou notas ornamentais, da presença modal.

À guisa de ilustração, observamos três dos temas de Sacre onde não se devem descartar certas posturas comuns. Primeiramente, o tema inicial de L'adoration de la terre, quando o fagote emprunte muito livremente uma das versões do tema do hino a Apolo, 


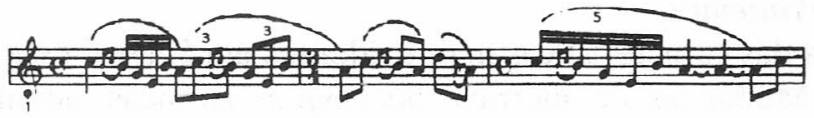

Pode-se entender como pertencente a um clima muito afim, um tema do cercle mystérieux des adolescents, exposto pela flauta em sol:

Exemplo 6,
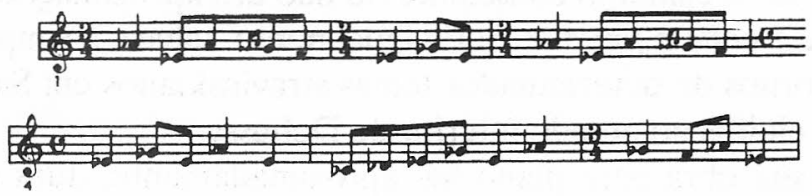

ou mesmo um tema de Rondes printanières executado pelas clarinetas:

Exemplo 7
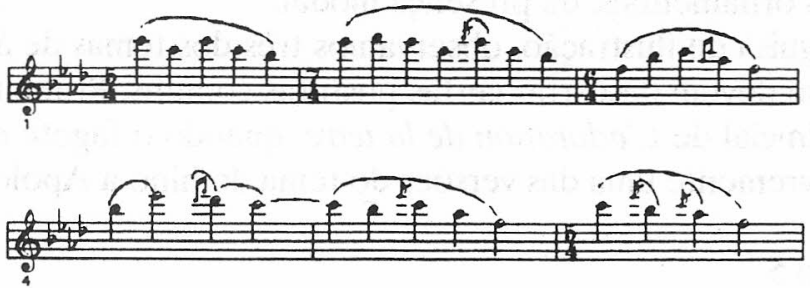
De La boîte à joujoux citaríamos, a título comparativo, três temas. Um primeiro, do Prélude initial ( $1^{\circ}$ quadro):

Exemplo 8 (pág. 1)

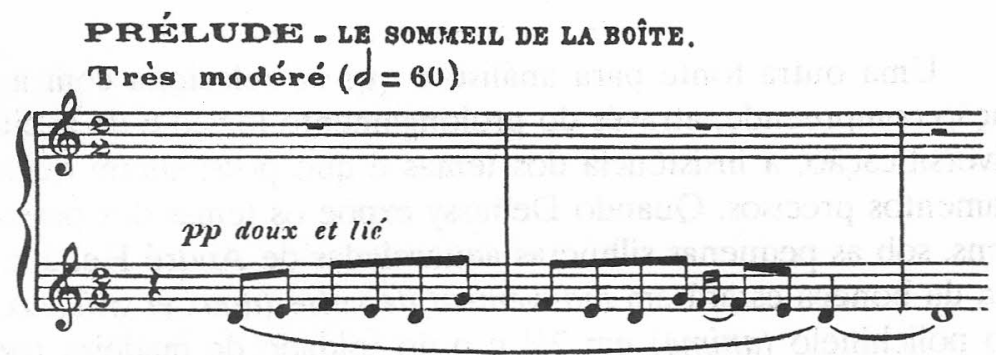

Um segundo, do início do $2^{\circ}$ quadro:

Exemplo 9 (pág. 25),

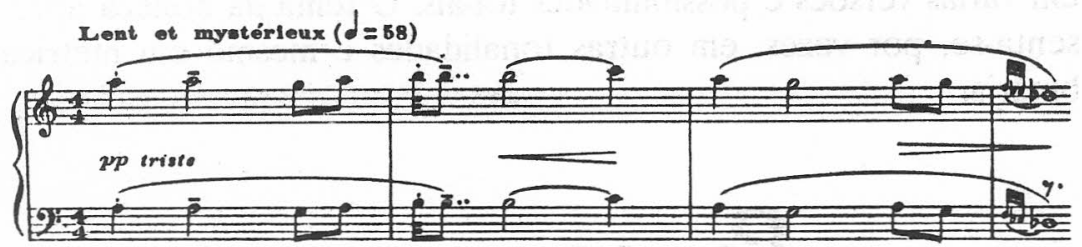

ou mesmo o tema da prece da boneca e, em seguida, a batalha, igualmente no segundo quadro:

Exemplo 10 (pág. 32)
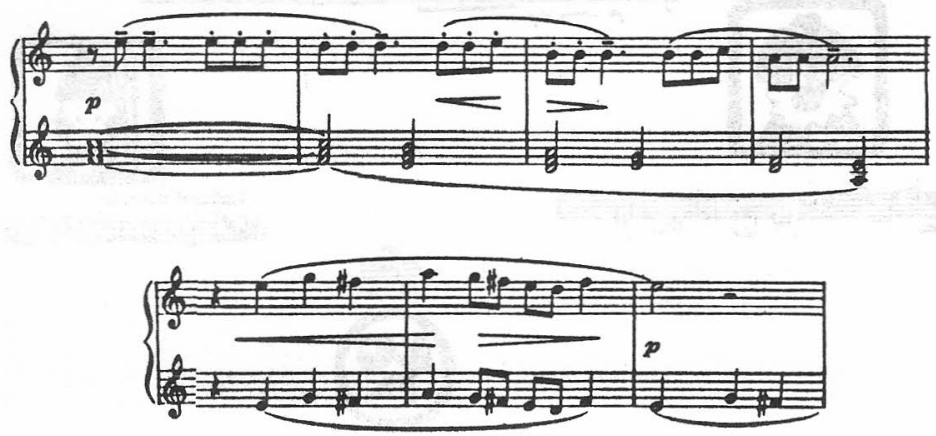
Isto posto, fica a possibilidade paradoxal que teria levado Debussy, da torrente telúrica que é Sacre, a extrair a gênese do despojamento, a síntese essencial do material que buscará o vir a ser.

\section{$* * *$}

Uma outra fonte para análise e que se relaciona com a duração compreende, através do prolongamento lógico e da já citada diversificação, a insistência dos temas e que possibilitam questionamentos precisos. Quando Debussy expõe os temas dos personagens, sob as pequenas silhuetas aquareladas de André Hellé, o tema da boneca estará em mouvement de valse (doux et gracieux), o do polichinelo (animé) em $2 / 4$ e o do soldado de madeira (gentiment militaire), sendo que o tema da rosa ficará representado por uma pausa de semínima em $p p$ decrescente. Polichinelo, o vilão, não mais estará presente durante o Prélude, mas "seus" intervalos de segundas, no caso, agressivos, percorrem a história, disfarçados em várias versões e possibilidades tonais. $\mathrm{O}$ tema da boneca apresenta-se, por vezes, em outras tonalidades e mesmo em métrica binária.

\section{Personnaces}

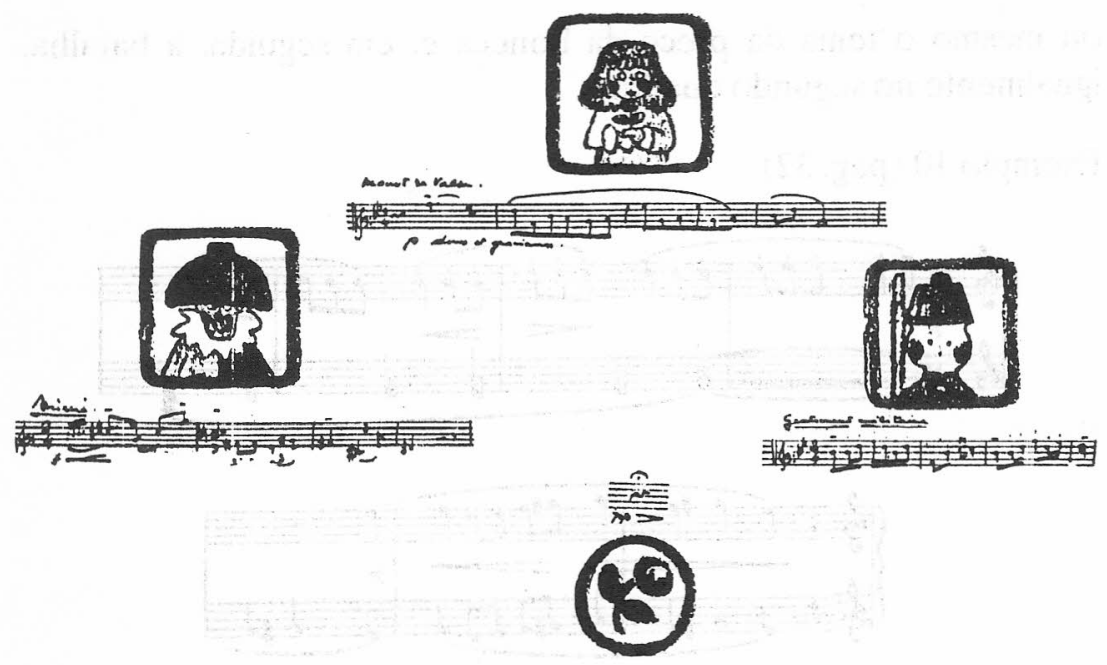


Do triângulo, seria talvez o soldado aquele que proporciona um questionamento mais delicado. Ainda há nuvens sobre um posicionamento real de Debussy frente ao militarismo. Sabe-se ainda pouco a respeito das impressões profundas que a prisão de seu pai durante a Comuna lhe causaram. Há mesmo, por parte de Debussy, uma parcimônia quanto ao externar seus sentimentos relacionados aos primeiros anos. Seria possível acreditar-se num imobilismo ver$\mathrm{bal}$, que extrapolaria quando do ato da composição.

Em La boîte à joujoux, o tema do soldado está sempre imutável quanto à sua prefiguração tonal. Esta imobilidade levaria às perguntas: haveria além do trompete em si bemol, uma razão para esta atitude? Não poderia Debussy, assim como o fez com os outros temas, revisitá-los em atonalidades outras?

O tema do soldado não muda de tonalidade, mas, paradoxalmente provoca sempre bitonalidades, graças às funções do acompanhamento:

Exemplo 11 (pág. 3)
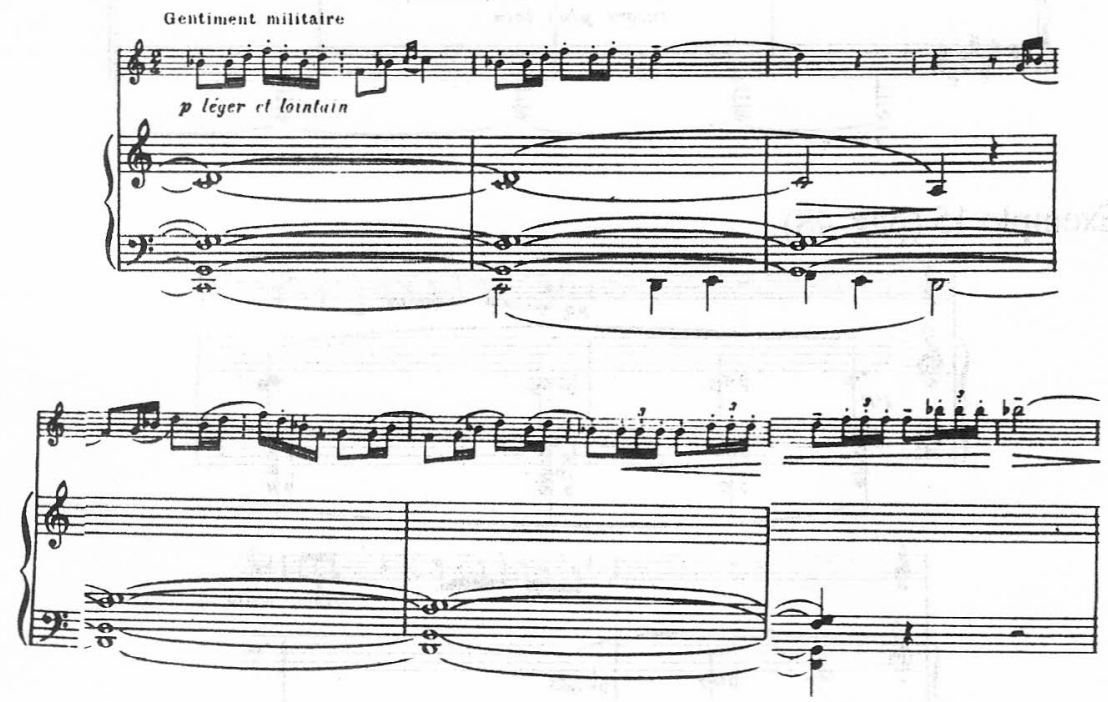
Exemplo 12 (pág. 6)

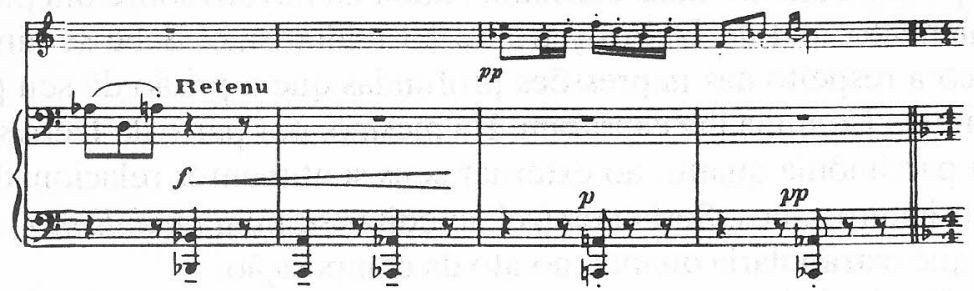

Exemplo 13 (pág. 35)

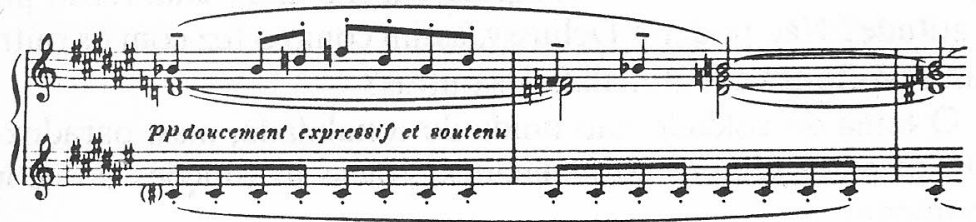

Exemplo 14 (pág. 36)

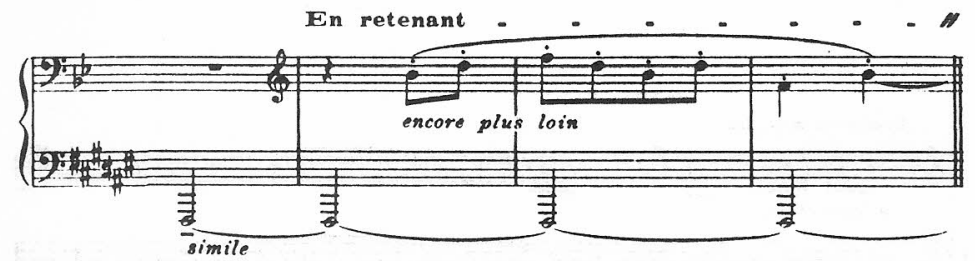

Exemplo 15 (pág. 48)
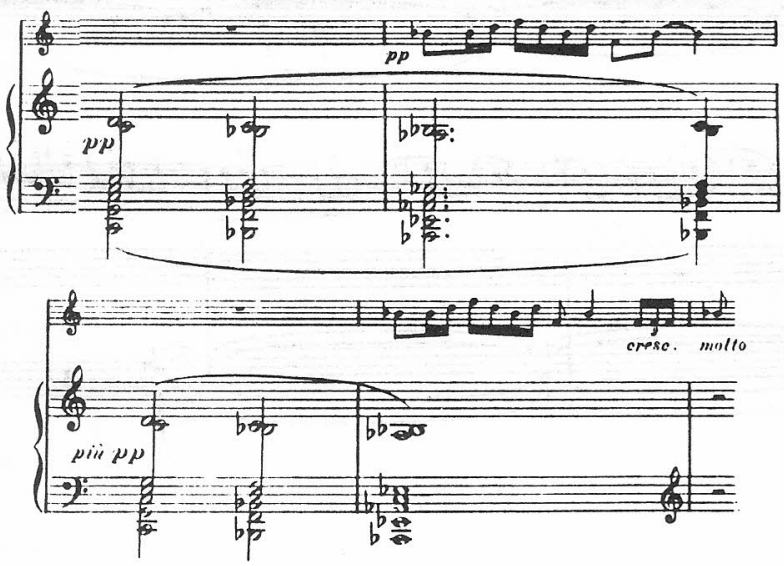
Um exemplo significativo, que apresenta os temas principais sucessivamente expostos, encontra-se na página 19 das Éditions Durand. A tonalidade é Ré bemol maior. No baixo, a Dominante em trinado sustenta inicialmente o tema da boneca na mesma tonalidade de Ré bemol, apresentando-se logo após, contudo, o tema do soldado em Si bemol:

Exemplo 16 (pág. 19)
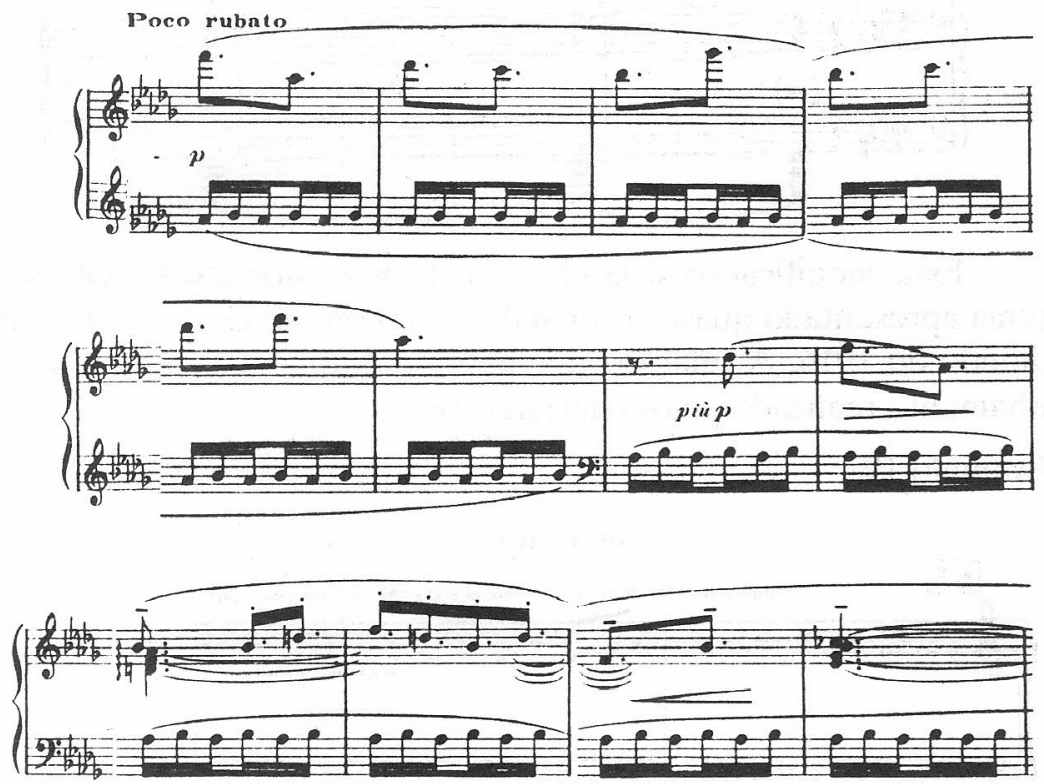

Significativa, igualmente, a apresentação do motivo "arpejado" do tema do soldado estruturado em centro tonal de Mi bemol:

Exemplo 17 (pág. 31)

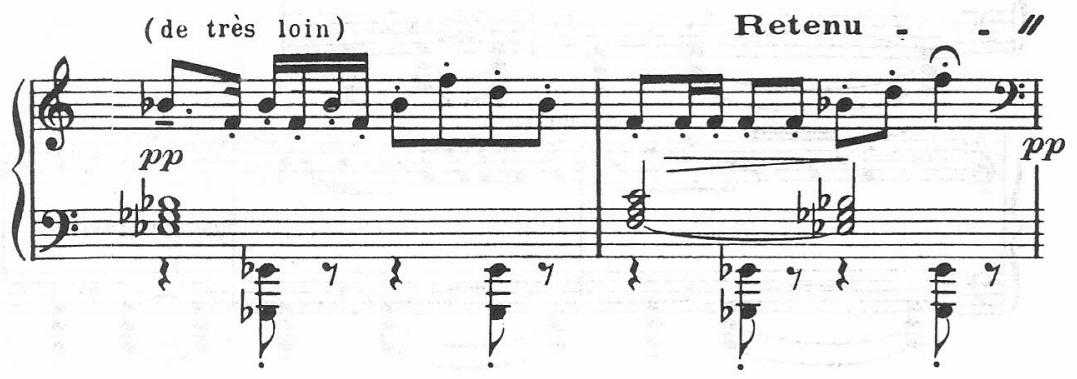


Quando, em 1914, Debussy compõe um fragmento que é , catalogado Noël de 1914, catalogado por François Lesure como obra de caractère domestique ou amical ${ }^{23}$, o autor utilizará o mesmo tema, empregando contudo um centro tonal de Fá sustenido:

Exemplo 18

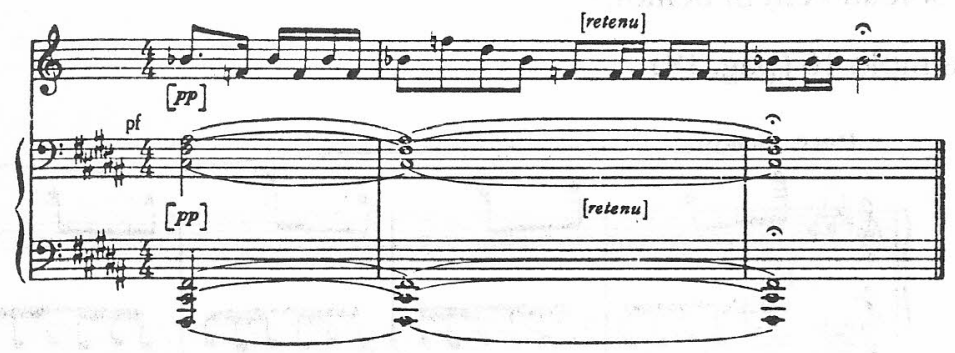

Esta modificação é conhecida. Como curiosidade, cite-se o tema apresentado quase ao final de Il Tabarro de Giacomo Puccini, datado de 1916. A relação igualmente é bitonal, sendo o acompanhamento realizado pelos contrabaixos 24 :

Exemplo 19

sostenuto

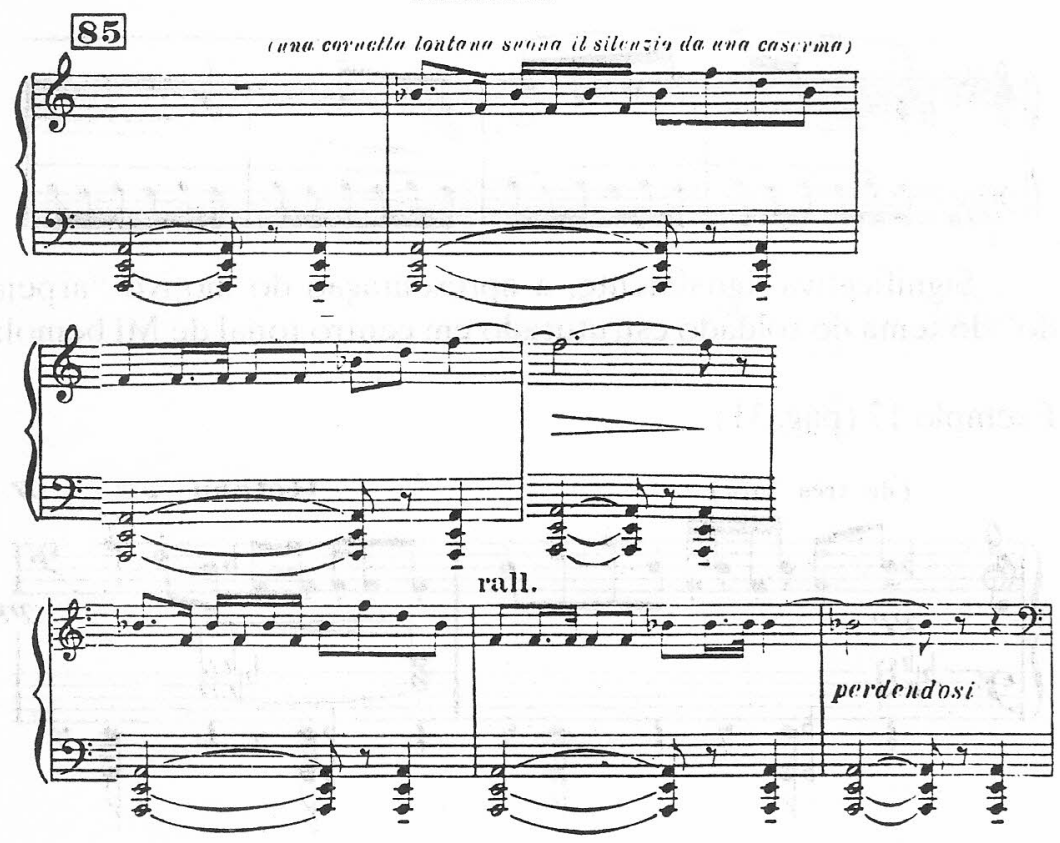


Torna-se evidente que, em todos os exemplos citados, a bitonalidade apenas dimensiona o questionamento da utilização de um tema de índole militar caracterizando um "antagonismo", se forem considerados aspectos tradicionalizados da obra como um todo.

Quanto à página 45 das Éditions Durand, "le soldat avec une grande barbe blanche, s'appuie sur un coffre fort" em Maestoso e com a indicação très important, poder-se-ia considerar como a plena descontração e ironia. Talvez, não por acaso, Debussy tenha apresentado o tema em oitavas, na região grave do piano, executado pela mão esquerda e os acordes da mão direita não provocando mais a evidência bitonal. Trata-se de uma questão que mereceria um aprofundamento.

\section{Exemplo 20 (pág. 45)}
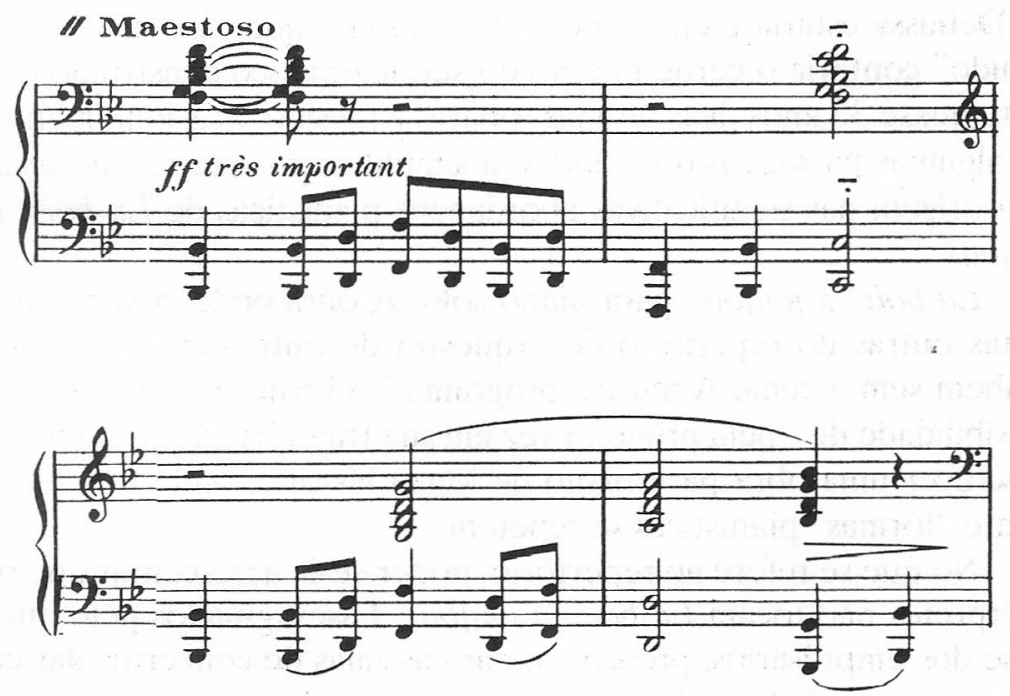

Para um músico intelectual como Debussy, a presença militarista não seria uma vizinhança que mereceria ser deixada à parte? Este aspecto "sugere", até o presente, um dos mistérios debussinianos a ser desvelado. Mencionem-se ainda dois exemplos, entre outros, na obra para piano de Debussy. No final de Feux d'Arifice, o autor emprega o tema da Marselhesa em Dó maior, sustentado por pedal em tremolo Ré bemol, Lá bemol; na Berceuse Heroüque, a presença do trompete em temas de cunho militar estará sustentada em situação bitonal. 
Sob outra égide, as insistentes indicações de Debussy au loin quando da evocação do trompete não seriam evidências que ultrapassam as fronteiras unicamente timbrísticas? A condição bitonal não sugeriria uma espécie de choque que ultrapassaria também as fronteiras apenas musicais?

Se La boîte à joujoux pode ser entendida como uma obra de síntese de muitos procedimentos pianísticos de Debussy, sob outro aspecto, o idiomático técnico-pianístico nela contido, onde há a essência de processos econômicos, permite compreendê-la como um todo resultante da depuração. "As inúteis acrobacias" pianísticas certamente não teriam sido oralizadas pelo compositor por acaso. Debussy estaria plenamente consciente de que esse piano "resumido" conteria o cerne mesmo do seu idiomático construído durante quase 35 anos. Nas últimas sonatas e mesmo, ocasionalmente, em algumas passagens dos Études, a simplificação que resulta teria uma origem nas significativas abordagens pianísticas de La boîte à joujoux

La boîte à joujoux para piano solo. A obra pode, assim como tantas outras do repertório de orquestra de outros autores, viver também sem a cena. A música programática forneceu a Debussy a possibilidade de - pela primeira vez em sua trajetória de compositor - escrever uma obra para piano de longa história, onde rarissimamente "fôrmas" pianísticas se repetem.

No que se refcre ao repertório, poder-se-ia acrescentar que os intérpretes não tocam La bô̂te à joujoux. Esses, guiados pelo interesse dos empresários, preservam para as salas de concertos das cidades as mais habituadas ao convívio musical, o repertório mais tradicional. Cláudio Arrau diria a Joseph Horowitz que, em torno de sua estréia nos Estados Unidos, nos anos 40, obras como Kreisleriana ou Davidsbündlertänze "(...) simplesmente não se tinha o direito de tocar! (...) O concerto de Schumann era considerado um suicídio"25. Apresentou Arrau, na ocasião, o Carnaval op. 9, aceita por empresários e pelo público e ainda hoje uma das obras mais tocadas de Schumann.

Debussy situa-se entre os mais frequentados compositores, sendo que algumas de suas obras são executadas quase sempre na 
íntegra, como: Suite Bergamasque, Pour le Piano, Images I e II, Children's Corner. Algumas peças isoladas, como as Arabesques, Rêverie, La plus que lente pertencem habitualmente ao universo executado extraprograma, o bis tradicional. O enigmatismo de Masques não é quase jamais desvelado e L'isle joyeuse continuaria a ser um cavalo de batalha nos concursos de piano e nas salas de concerto. A integral dos Préludes é rara. Estes, assim como mais raramente os Études, pertencem àquelas obras onde o público identifica-se com umas poucas entre as peças constituintes, em princípio, sempre as mesmas. A falta de inovação por parte do intérprete, sobretudo os pianistas, é infelizmente bem conhecida.

Haverá necessidade de um esforço para tornar La boîte à joujoux uma obra do repertório habitual de longa duração, sobremaneira. Ela tem todạs as qualidades necessárias, a partir, por coincidência, dos seus reais três quadros ininterruptos. Depositária dos conhecimentos os mais abrangentes por parte de Debussy, La boîte à joujoux mantém, conseqüentemente, em seus elos encadeados, uma sólida unidade que a coloca como a obra de maior duração para piano, programática e também uma criação única através de suas características.

La boîte à joujoux, por vezes minimizada por determinados autores por falta de uma revisão de conceitos, perde com a atitude destes a possibilidade da multidirecionalidade. Sob outro aspecto, aquela posição distancia os intérpretes de La boîte à joujoux, que poderão compreender, se quiserem, o exemplo pianístico de Debussy o mais fiel ao espírito de síntese que nortearia o compositor em seus últimos anos.

Seria necessário, para isso, além do espírito cênico real, evidenciar La boîte à joujoux, independentemente de sua própria história - também no senso abstrato e simplesmente interpretá-la com simplicidade devida.

A obra merece essa reparação.

\section{NOTAS}

* Comunicação apresentada na École Pratique des Hautes Études Universidade de Paris, Sorbonne, aos 16 de janeiro de 1992.

1. LESURE, François. Catalogue de l'oeuvre de Claude Debussy. Genève, Minkoff, 1977, p. 156. 
2. HALBREICH, Henry. "Analyse de l'oeuvre". In: LOCKSPEISER, Edward. Debussy. Paris, Fayard, 1980, pp. 742-744. Trad. francesa.

3. ORLEDGE, Robert. Debussy and the theatre. Cambridge, Cambridge University Press, 1982, pp. 177-185.

4. LESURE, op. cit., p. 137.

5. ORLEDGE, op. cit., pp. 177-185.

6. DIÉTSCHY, Marcel. La passion de Claude Debussy. Neuchâtel, A La Baconnière, 1962, p. 264.

7. DEBUSSY, Claude. Lettres de Claude Debussy à son éditeur: Paris, Durand, 1927 , p. 190.

8. Paris, Hermann, 1980, p. 243.

9. Monsicur Croche et autres écrits. Introdução e notas por François Lesure. France, Gallimard, 1987, p. 329.

10. Lettres de Claude Debussy à son éditeur, p. 116.

11. Monsieur Croche et autres écrits, p. 330.

12. LOCKSPEISER, Fidward. Debussy: His life and mind, Cambridge, Cambridge University Press, 1978, p. 178. Lembre-se de que L'enfant et son sortilège foi editado pelas Éditions Durand em 1925, ilustrada por André Hellé, igualmente.

13. HALBREICH, op. cit., p. 743.

14. ORLEDGE, op. cit., p. 185.

15. DIÉTSCHY, op. cit., p.223.

16. CORTOT, Alfred. La musique française de piano, I. Paris, P.U.F., 1948; Robert SCHMITZ, The piano works of Claude Debussy. New York, Dover, 1966; ZULUETA, Jorge e ROMANO, Jacobo, La obra completa para piano. Buenos Aires, Universidade Nacional de Tucuman, 1964.

17. DEBUSSY, Lettres de Claude Debussy à son éditeur, p. 115.

18. Anteriormente, tivemos um ensaio publicado abordando a influência consciente ou não de Moussorgsky sobre La boîte à joujoux de Debussy. MARTINS, José Eduardo. "La vision de l'univers enfantin chez Moussorgsky et Debussy". In: Cahiers Debussy. Saint-Germanin-en-Laye, Centre de Documentation Claude Debussy, 9:3-16, 1985. Nouvelle Série.

19. DEBUSSY, Lettres - 1884-1918., p. 233.

20. LOCKSPEISER, op. cit., p. 180.

21. LALOY, I.ouis. La musique retrouvée (1902-1927). France, desclée de Brouwer, 1974 , p. 213.

22. LOCKSPEISER, op. cit., p. 181.

23. LESURE, op. cit., p. 151 . Noël pour 1914 ... pour I voix et accompagnement de piano (Bibl. Nat. Ms. 14521).

24. Observe-se, à guisa de curiosidade, a utilização do final do tema do soldade de La boîte à joujoux no Le pique-nique de Sports et divertissements de Erik Satie, escrito em abril de 1914.

25. ARRAU, Claudio. Amau parle. Conversations avec Joseph Horowitz. Paris, Gallimard, 1982, p. 104.

José Eduardo Martins é pianista e professor associado do Departamento de Música da ECA-USP. 